\title{
Socioeconomic determinants of accessibility to birth registration in Lao PDR
}

\author{
Marika Nomura ${ }^{1 *}$ D, Phonepadith Xangsayarath ${ }^{2}$, Kenzo Takahashi ${ }^{3}$, Yusuke Kamiya $^{4}$, Latsamy Siengsounthone ${ }^{2}$, \\ Hina Ogino ${ }^{5}$ and Jun Kobayashi ${ }^{6}$
}

\begin{abstract}
Background: The global coverage rate of birth registration is only around $65 \%$ for the population of children under five although birth registration secures protection and access to health services that are fundamental rights for all babies. This study aimed to perform a basic analysis of the accessibility to birth registration to better understand how to improve the birth registration system in the Lao PDR.

Methods: For the analysis of birth registration and related socioeconomic factors, 9576 mother-child pairs were chosen from the data set of The Lao Social Indicator Survey 2011-12. After bivariate analysis with statistical tests including the chi-square test were conducted, logistic regression was performed to determine the variables that statistically influence accessibility to birth registration.

Results: Ethno-geographic factors and place of delivery were observed to be the factors associated with birth registration in this analysis.

Conclusion: Many mothers in the Lao PDR deliver in their local communities. Therefore, capacity development of various human resources, such as Skilled Birth Attendant, to support the local administrative procedure of birth registration in their communities could be one option to overcoming the bottlenecks in the birth registration process in the Lao PDR.
\end{abstract}

Keywords: Birth registration, Socioeconomic factors, Capacity development, Home delivery, Lao PDR

\section{Background}

Under the Convention of the Rights of the Child, all children have the right to have a legally registered name, to be officially recognized by the government and also to have a certified nationality [1]. However, globally, almost 230 million children have never been officially registered according to a 2013 UNICEF report [2]. Birth registration secures protection and access to health services that are fundamental rights for all babies. According to previous reports, political stance, law, human rights and economic, cultural, gender, geographical and domestic security issues are cited as possible bottlenecks in birth registration $[3,4]$.

Basic demographic data collected by birth registration are crucial information for national planning and

\footnotetext{
* Correspondence: nomuraba-jp@umin.net

'Department of International Health and Collaboration, National Institute of

Public Health, 2-3-6 Minami, Wako-shi, Saitama 351-0197, Japan

Full list of author information is available at the end of the article
}

monitoring because they enable the creation of effective strategies not only for the health sector but for all sectors of development $[5,6]$. The registration of births is fundamental to ensure civil and political rights including those of enrollment of children in school at the appropriate age and their right of access to appropriate healthcare [7]. In addition, the legal acknowledgement of a child's existence protects the child from various deprivations such as child trafficking, under-age participation in the military and forced marriage $[5,8]$.

According to the 2013 UNICEF report, the coverage rate of birth registration is only around $65 \%$ of the population of children under five worldwide [2]. The low coverage of birth registration in Asian and Sub-Saharan African countries implicates various complicated factors such as geographical conditions or socioeconomic situations as possible bottlenecks, especially in remote communities. The results from Ghana indicated that birth registration is a privilege for children whose 
parents are educated, wealthy and living in urban communities [9]. In Nigeria, age, level of education, marital status, occupation, place of delivery, attended antenatal care and food availability at home were the factors related to the accessibility to birth registration $[10,11]$. Although the bottlenecks have been investigated from various angles in Africa, exploration of the socioeconomic factors of the practice of birth registration in Southeast Asia remains inadequate.

The Lao PDR, the subject country of this analysis, has a rate of birth registration of $75 \%$ according to the 2015 UNICEF report [12]. This figure, along with other maternal and child health indicators, is one of the lowest among the ASEAN countries (Table 1). In the Lao PDR, a series of family registrations, such as birth registration, is provided for under the "Family Registration Law" [13]; however, the actual practice of birth registration in the community seems to be hard to achieve because in the Lao PDR, many mothers deliver their children at home in their local communities, which accounts for $75 \%$ of the total deliveries. In this unique context, delivery conditions, which are included as a part of social determinants [14], are likely to be a predominant factor related to the accessibility to birth registration in the Lao PDR [12].

Therefore, this study aimed to perform a basic analysis of the accessibility to birth registration to better understand methods to improve the birth registration system in the Lao PDR and to determine policy implications for overcoming the difficult achievement of birth registration in Lao PDR, where most mothers choose home delivery.

\section{Methods}

\section{Data}

We used data from the 2011-12 Lao Social Indicator Survey (LSIS) in the present analysis. The LSIS is a household-based survey that applies the technical frameworks of the Multiple Indicator Cluster Survey and the Demographic and Health Survey [15]. LSIS was conducted to monitor the progress towards the Millennium Development Goals and to serve as a baseline for the 7th National Socio-Economic Development Plan [16]. Field data were collected from October 2011 to February 2012. Among the 18,843 households interviewed nationally in the survey, 97,421 household members were listed. Of these, 47,820 were men and 49,601 were women. The average household size found in the survey was 5.2 persons.

The response rates for households, women and men were $99 \%(18,843 / 19,018), 94 \%(22,476 / 23,937)$ and $89 \%$ $(9951 / 11,166)$, respectively. Detailed information was obtained via interview on 11,067 (98\%) of the 11,258 children under 5 years of age listed in the household questionnaire. Face-to-face interviews were conducted with all women aged 15-49 years and men aged 1559 years in the sampled households by use of questionnaires covering socioeconomic, demographic and health indicators.

The survey covers a broad range of topics including water and sanitation, marriage and sexual activity, fertility levels and trends, reproductive health, adult and maternal mortality, child health, nutrition, child mortality, child development, literacy and education, child protection, HIV/ AIDS and sexual behavior, access to mass media and use of information/communication technology.

\section{Statistical analysis}

Values related to the accessibility to birth registration across the categories of the explanatory variables are presented as numbers and percentages. The outcome indicator of birth registration includes children whose parents self-reported the possession of a birth certificate and children whose mother or caretaker said that the birth had been registered [15].

From the LSIS data set, 9576 mother-child pairs for which complete data on socioeconomic stat was available were used for the analysis of birth registration and related socioeconomic factors.

First, bivariate analysis was conducted to explore the proportion of children registered with respect to each socioeconomic factor. Statistical tests including the chisquare test were used to test whether there were significant associations between the responses about birth registration and the socioeconomic factors. The analysis used 14 socioeconomic factors at the child, maternal, household and community levels: child's sex, child's age in months, maternal age, marital status, maternal educational attainment, experience of delivery, experience of child loss, paternal educational attainment, head of household's ethnicity, head of household's ethno-language, head of household's religion, wealth index quintiles, region and settlement. Bivariate analysis was also performed to clarify the relationships between place of delivery, delivery attendance and birth registration. Finally, we used logistic regression to explore the variables that statistically influenced accessibility to birth registration by preparing 3 logistic models (model 1 included "maternal, household and community variables only"; model 2 included "maternal, household, community variables and skilled birth attendant (SBA) attendance"; and model 3 included "maternal, household, community variables, SBA attendance and place of delivery"). All analyses were done using IBM SPSS Statistics for Windows, Version 24.0.

\section{Results}

Figure 1 shows the geographical distribution of birth registration among the 17 provinces in the Lao PDR. 


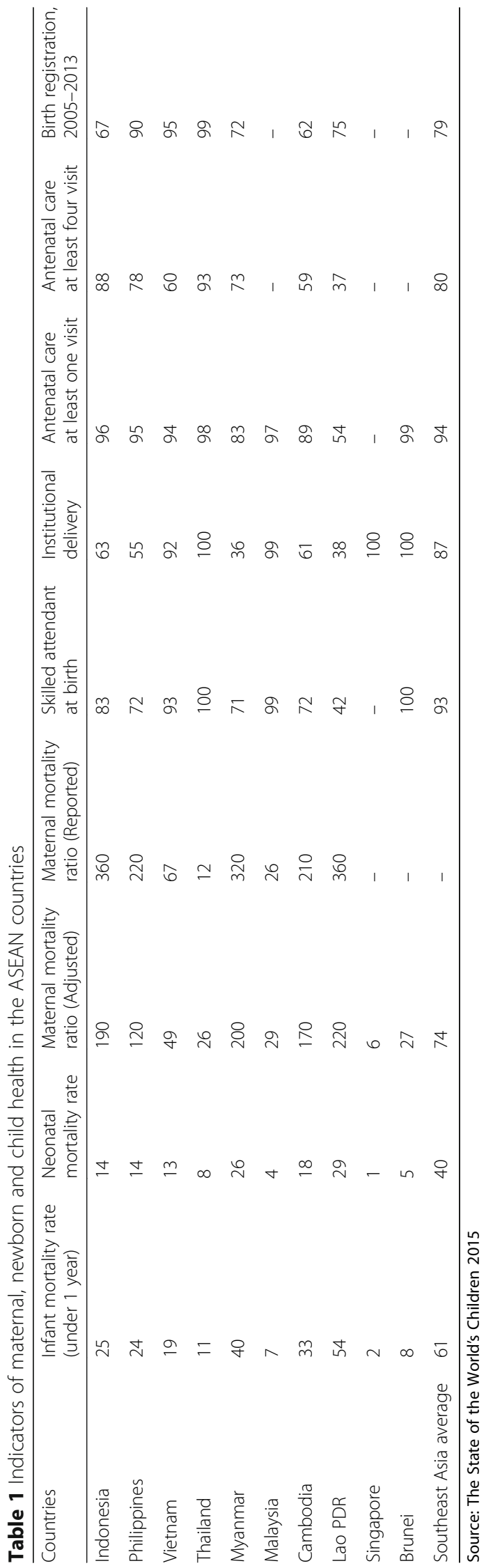




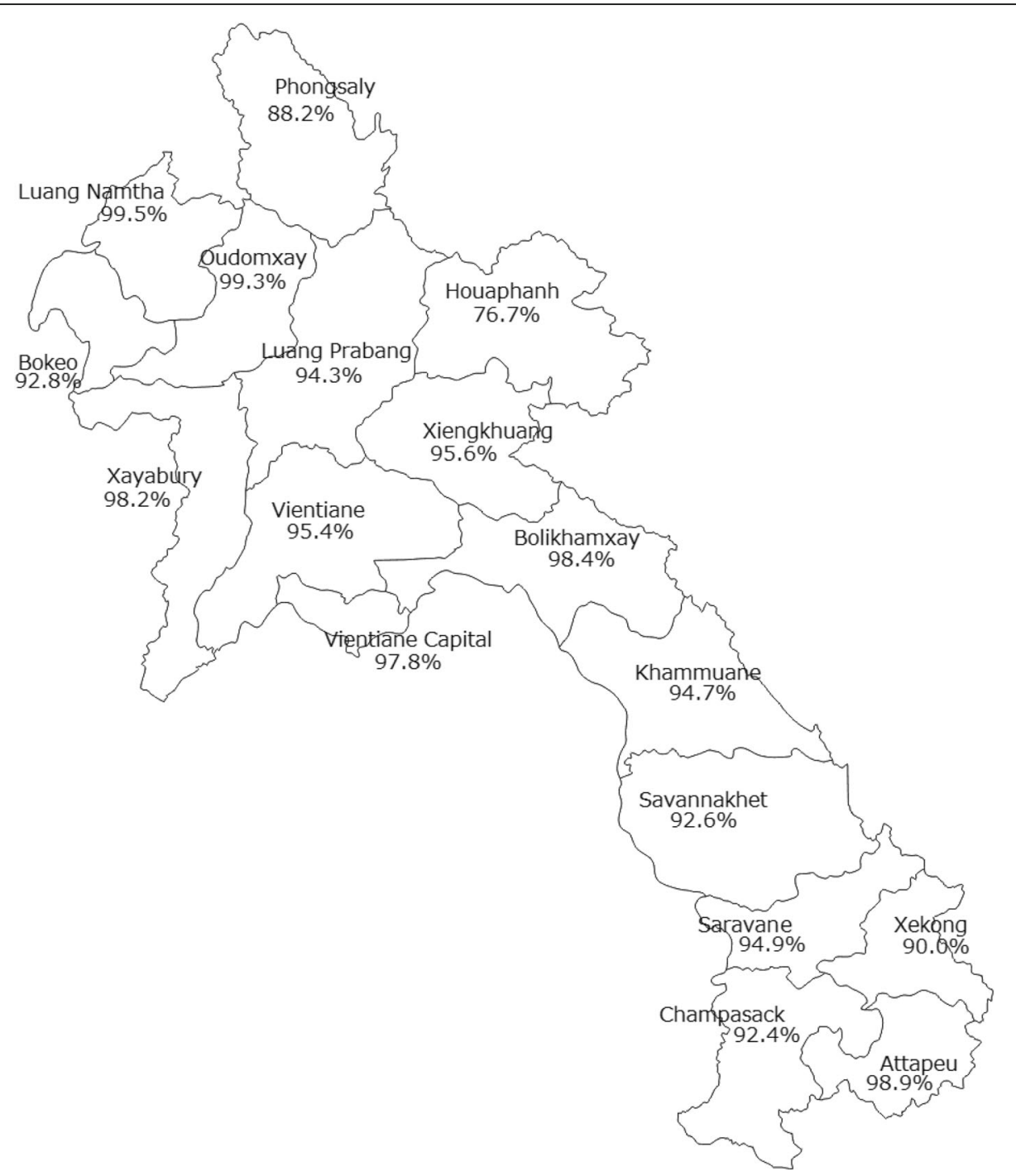

Fig. 1 Geographical distribution of the percentages of birth registrations by province in the Lao PDR. The original map was retrieved from the URL below and licensed under the Creative Commons Attribution 2.5 Generic license. Https://commons.m.wikimedia.org/wiki/ File:Laos_provinces_blank.png is provided by Wikipedia with common license

Apart from most of the provinces, which have almost $100 \%$ birth registration, only Huaphanh province in the North had a significantly low percentage of $76.7 \%$. Vientiane Capital, site of the national capital, reported relatively high coverage of birth registration.

Table 2 presents the proportions of children between the ages $0-59$ months who have birth registration according to child, maternal, household and community factors. Corresponding levels of association between the independent variables and the dependent variable are also indicated based on chi square test results. There was no association between child sex and birth registration. Children whose mothers had experienced child loss had less access to birth registration. Children whose parents had higher levels of education were more likely to have birth registration than those whose parents had a lower level of education. For instance, rates of access to birth registration by children according to the mother's educational level were as follows: no education, $66.3 \%$; primary education, $75.1 \%$; secondary education, $83.9 \%$ and higher education, $93.8 \%$. The trend was clearer than that for the father's educational attainment. Rates of access to birth registration by children according to the father's educational level were as follows: no education, $66.6 \%$; primary education, $71.1 \%$; secondary education, $79.6 \%$ and higher education, 92.7\%. Similar patterns were observed with higher household wealth. In terms of ethnicity, only $57.1 \%$ of the Khmer ethnic group had access to birth registration. Only $68.1 \%$ of Animists had access to birth registration, in contrast to $81.4 \%$ of Buddhists. 
Table 2 Relationship between child factors, maternal factors, household factors, community factors and birth registrations, Lao PDR $(n=9576)$

\begin{tabular}{|c|c|c|c|}
\hline \multirow{3}{*}{ Independent factors } & \multicolumn{2}{|c|}{ Birth registration } & \multirow{3}{*}{$P^{a}$} \\
\hline & Yes & No & \\
\hline & (\%) & (\%) & \\
\hline
\end{tabular}

\begin{tabular}{llllll}
\hline $\begin{array}{l}\text { Child factors } \\
\text { Child sex }\end{array}$ & & & & & \\
Male & 3580 & 73.7 & 1276 & 26.3 & 0.174 \\
Female & 3537 & 74.9 & 1183 & 25.1 &
\end{tabular}

Child age ${ }^{\mathrm{b}}$ (months)

$\begin{array}{lllll}0-11 & 1222 & 60.4 & 796 & 39.4 \\ 12-23 & 1406 & 74.0 & 494 & 26.0 \\ 24-35 & 1410 & 76.4 & 436 & 23.6 \\ 36-47 & 1589 & 80.7 & 379 & 19.3 \\ 48-59 & 1490 & 80.8 & 354 & 19.2\end{array}$

Maternal factors

Maternal age ${ }^{\mathrm{b}}$ (years)

$\begin{array}{lllll}15-19 & 443 & 65.4 & 234 & 34.6 \\ 20-29 & 4041 & 74.5 & 1386 & 25.5 \\ 30-39 & 2179 & 76.1 & 686 & 23.9 \\ 40-49 & 454 & 74.8 & 153 & 25.2\end{array}$

Marital status

$\begin{array}{lllll}\text { Never } & 30 & 71.4 & 12 & 28.6 \\ \text { Married } & 7083 & 74.3 & 2447 & 25.7 \\ \text { Divorced } & 2 & 100.0 & 0 & 0.0 \\ \text { Widowed } & 2 & 100.0 & 0 & 0.0\end{array}$

Maternal educational attainment ${ }^{b}$

$\begin{array}{lllll}\text { No education } & 2229 & 66.3 & 1131 & 33.7 \\ \text { Primary } & 2969 & 75.1 & 982 & 24.9 \\ \text { Secondary } & 1738 & 83.9 & 334 & 16.1 \\ \text { Higher } & 181 & 93.8 & 12 & 6.2\end{array}$

Ever given birth

$\begin{array}{lllll}\text { Yes } & 7105 & 74.3 & 2458 & 25.7 \\ \text { No } & 12 & 92.3 & 1 & 7.7\end{array}$

Ever experienced loss of a child ${ }^{b}$

$\begin{array}{lllll}\text { Yes } & 1703 & 69.2 & 759 & 30.8 \\ \text { No } & 5414 & 76.1 & 1700 & 23.9\end{array}$

Household factors

Father's educational attainment ${ }^{\mathrm{b}}$

$\begin{array}{lllll}\text { No education } & 1015 & 66.6 & 510 & 33.4 \\ \text { Primary } & 3094 & 71.1 & 1257 & 28.9 \\ \text { Secondary } & 2575 & 79.6 & 658 & 20.4 \\ \text { Higher } & 433 & 92.7 & 34 & 7.3\end{array}$

Ethnicity of $\mathrm{HHH}^{\mathrm{b}}$

Lao

$$
<0.001
$$

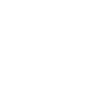

9.2

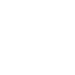


Table 3 Relationship between delivery place and birth attendance and birth registration, Lao PDR

\begin{tabular}{|c|c|c|c|c|c|}
\hline \multirow{3}{*}{ Independent factors } & \multicolumn{4}{|c|}{ Birth registration } & \multirow{3}{*}{$\mathrm{P}^{\mathrm{a}}$} \\
\hline & \multicolumn{2}{|l|}{$\overline{\text { Yes }}$} & \multicolumn{2}{|l|}{ No } & \\
\hline & $\bar{n}$ & $\overline{(\%)}$ & $\mathrm{n}$ & $\overline{(\%)}$ & \\
\hline \multicolumn{6}{|l|}{ Delivery place ${ }^{b}$} \\
\hline Hospital & 1240 & 85.1 & 217 & 14.9 & \multirow[t]{5}{*}{$<0.001$} \\
\hline Health center & 130 & 68.4 & 60 & 31.6 & \\
\hline Private facility & 34 & 89.5 & 4 & 10.5 & \\
\hline Home & 2535 & 65.0 & 1368 & 35.0 & \\
\hline Other & 73 & 38.4 & 117 & 61.6 & \\
\hline \multicolumn{6}{|l|}{ Skilled birth attendant ${ }^{b}$} \\
\hline Yes & 1422 & 79.3 & 370 & 20.7 & \multirow[t]{2}{*}{$<0.001$} \\
\hline No & 5695 & 73.2 & 2089 & 26.8 & \\
\hline \multicolumn{6}{|l|}{$\mathrm{TBA} / \mathrm{CHW}$} \\
\hline Yes & 588 & 72.2 & 226 & 27.8 & \multirow[t]{2}{*}{0.155} \\
\hline No & 6529 & 74.5 & 2233 & 25.5 & \\
\hline
\end{tabular}

TBA/CHW: Traditional birth attendant/Community health worker aP-value was calculated for chi square tests (categorical variables)

${ }^{\mathrm{b}}$ Correlation between the independent variable and birth registration/birth certificate is statistically significant at the 0.05 level, and the variable was included in further logistic regression analyses

private facility (89.5\%). Attendance by a SBA seem to encourage mothers to obtain birth registration. In contrast, delivery with a traditional birth attendant/community health worker (TBA/CHW) did not seem to result in mothers obtaining a birth registration for their newborns; there was no significant difference between TBA/CHW and birth registration.

Logistic regression analysis was applied to determine the variables that statistically influenced the attainment of birth registration. Variables that were of no significance, variables related to the child and variables that had collinearity were excluded from the analysis beforehand. The results are presented in Table 4.

Maternal age was the significant factor for birth registration, rather than maternal educational attainment, in model 1. Higher educational attainment of the father and higher household wealth were likely to accelerate registration of a child's birth. Khmer people were significantly less likely to have access to birth registration. SBA attendance was not associated with accessibility to birth registration. SBA attendance was excluded in model 2 and thus had no association with birth registration. In model 3, place of delivery, experience of child loss, religion and household index were not associated with birth registration in contrast to the results in models 1 and 2 . As expected, children who were born in a community were less likely to have birth registration: $46 \%$ in health centers, $53 \%$ at home and $85 \%$ in other locations.

\section{Discussion}

In this analysis, we illustrated the geographical distribution of birth registration, and then we examined variables related to the outcomes of birth registration. Ethnicity of the head of the household, settlement and delivery place were observed to be the important factors related to accessibility of birth registration in this analysis.

First, considerable geographical distribution was identified across all of the provinces. Accessibility in Huaphanh province and Pongsaly province in the Northern area was quite low compared with that in the Central and Southern areas. In the Lao PDR, the Northern area, in which ethnic minorities dwell, consists of a mountain range running along the border with China, Myanmar and Vietnam. In the multivariable analysis, settlement and ethnicity were the common factors that remained in all models, which means that ethno-geographic factors may determine the accessibility to birth registration. Even after adjustment for SBA attendance or place of delivery, settlement and ethnicity were still likely to be significant factors. Of great concern are the disparities between different regions in the nation, within regions and between urban and rural areas [2]. The possible reasons accounting for these ethno-geographic differences in birth registration in the Lao PDR are poor literacy in ethnic minority groups and poor accessibility by road especially in the Northern mountainous region. Thus, we surmise that the birth registration system is not working well in the mountainous remote areas where ethnic minorities dwell. For this reason, a community-based strategy targeting the people living in remote areas or ethnic minority groups is needed.

Because geographical disparity is a fundamental issue that cannot be avoided, we should further promote community-based intervention, which is in place everywhere in the Lao PDR. Considering the geographical disparities of accessibility to birth registration in many communities, community health volunteers ( $\mathrm{CHVs}$ ) assume a key role in issuing birth certificates and supervising the management of the family book in the Lao PDR. In some regions, $\mathrm{CHVs}$ work actively and have all of the information on vital statistics such as births or deaths [17-19]. Strengthening the monitoring and evaluation system of vital statistics by further enhancing the capacity of CHVs would be a useful measure because they may play an important role as the recorder of vital statistics in remote communities. Empowering village heads and administrative staffs who are in charge of managing vital statistics in a village to monitor the community population could be another possible approach. Furthermore, from a gender perspective, the father's higher education attainment was significantly associated with birth registration. Approaches to enlighten fathers' awareness 
Table 4 Odds ratios (95\% Cls) of birth registration by different models, Lao PDR

\begin{tabular}{|c|c|c|c|c|c|c|c|c|c|}
\hline & \multicolumn{9}{|c|}{ Birth registration } \\
\hline & \multicolumn{3}{|c|}{ Model $1^{a}$} & \multicolumn{3}{|c|}{ Model $2^{b}$} & \multicolumn{3}{|c|}{ Model $3^{c}$} \\
\hline & $O R$ & \multicolumn{2}{|l|}{$95 \% \mathrm{Cl}$} & $O R$ & \multicolumn{2}{|l|}{$95 \% \mathrm{Cl}$} & $O R$ & \multicolumn{2}{|l|}{$95 \% \mathrm{Cl}$} \\
\hline \multicolumn{10}{|l|}{ Maternal factors } \\
\hline \multicolumn{10}{|l|}{ Maternal age } \\
\hline $15-19$ & 1.00 & & & 1.00 & & & 1.00 & & \\
\hline $20-29$ & 1.45 & 1.21 & $1.73^{* * *}$ & 1.45 & 1.21 & $1.73^{* * *}$ & 1.35 & 1.12 & $1.64^{* * *}$ \\
\hline $30-39$ & 1.67 & 1.37 & $2.02^{* * *}$ & 1.67 & 1.37 & $2.02^{* * *}$ & 1.54 & 1.24 & $1.91^{* * *}$ \\
\hline $40-49$ & 1.83 & 1.41 & $2.37^{* * *}$ & 1.83 & 1.41 & $2.37^{* * *}$ & 1.49 & 1.06 & $2.10^{* *}$ \\
\hline
\end{tabular}

Maternal educational attainment

No education
Primary
Secondary
Higher

Ever experienced loss of a child

\begin{tabular}{|c|c|c|c|c|c|c|}
\hline No & 1.00 & & & 1.00 & & \\
\hline Yes & 0.86 & 0.76 & $0.96^{* *}$ & 0.86 & 0.76 & $0.96^{* *}$ \\
\hline
\end{tabular}

Household factors

Father's educational attainment

\begin{tabular}{|c|c|c|c|c|c|c|c|c|c|}
\hline No education & 1.00 & & & 1.00 & & & 1.00 & & \\
\hline Primary & 1.05 & 0.91 & 1.19 & 1.05 & 0.91 & 1.19 & 0.96 & 0.81 & 1.13 \\
\hline Secondary & 1.19 & 1.02 & $1.40 *$ & 1.19 & 1.02 & $1.40 * *$ & 1.11 & 0.92 & 1.35 \\
\hline Higher & 2.04 & 1.37 & $3.05^{* * *}$ & 2.04 & 1.37 & $3.05^{* * *}$ & 2.03 & 1.30 & $3.18^{* * *}$ \\
\hline
\end{tabular}

Ethnicity of $\mathrm{HHH}$

Lao
Khmu
Khmer
Other

$\begin{array}{lll}0.82 & 1.41 \quad 1.08\end{array}$

$\begin{array}{lllll}0.82 & 1.41 & 0.86 & 0.62 & 1.18 \\ 0.20 & 0.68^{* * *} & 0.42 & 0.19 & 0.92^{* *} \\ 0.52 & 0.77^{* * *} & 0.59 & 0.47 & 0.75^{* * *}\end{array}$

Ethno-linguistics of $\mathrm{HHH}$

Lao-Thai
Mon-Khmer
Hmong-Mien
Chinese-Tibetan

$0.77^{* * *}$

0.63

0.52

$0.77+4 *$

$1.72^{* * *}$
2.18
1.56

1.00

$\begin{array}{llll}1.20 & 0.67 & 2.18 & 1.20\end{array}$

0.67

1.64
1.12
1.07

1.27
0.51
0.77

Buddhist

Animist

Other

1.00

0.89

0.75

1.05

$2.40 * *$

0.89

1.51

$\begin{array}{ll}0.75 & 1.05 \\ 0.96 & 2.40^{*}\end{array}$

Wealth index quintiles

\section{Poorest}

2nd quintile

3rd quintile

4th quintile

Wealthiest
1.00

1.00

1.34

1.40

2.78
0.88

1.13

$1.57^{* * *}$

$1.70^{* * *}$

1.00

1.00

1.34

0.88

1.13

1.16

1.40

1.15

$1.57^{* * *}$

2.05

$3.77^{* * *}$

2.78

1.16

$1.70^{* * *}$

$2.05 \quad 3.77^{* * *}$ 
Table 4 Odds ratios (95\% Cls) of birth registration by different models, Lao PDR (Continued)

\begin{tabular}{|c|c|c|c|c|c|c|c|c|c|}
\hline & \multicolumn{9}{|c|}{ Birth registration } \\
\hline & \multicolumn{3}{|l|}{ Model $1^{a}$} & \multicolumn{3}{|l|}{ Model $2^{b}$} & \multicolumn{3}{|l|}{ Model $3^{c}$} \\
\hline & $\overline{O R}$ & $95 \% \mathrm{Cl}$ & & $\overline{O R}$ & $95 \% \mathrm{Cl}$ & & $\overline{O R}$ & $95 \% \mathrm{Cl}$ & \\
\hline \multicolumn{10}{|l|}{ Community factors } \\
\hline \multicolumn{10}{|l|}{ Settlement } \\
\hline Urban & 1.00 & & & 1.00 & & & 1.00 & & \\
\hline Rural w/ road & 0.62 & 0.52 & $0.74 * * *$ & 0.62 & 0.52 & $0.74^{* * *}$ & 0.63 & 0.51 & $0.77^{* * *}$ \\
\hline Rural w/o road & 0.39 & 0.31 & $0.49^{* * *}$ & 0.39 & 0.31 & $0.49^{* * *}$ & 0.38 & 0.30 & $0.49^{* * *}$ \\
\hline \multicolumn{10}{|l|}{ Delivery factors } \\
\hline \multicolumn{10}{|l|}{ Delivery place } \\
\hline Hospital & & & & & & & 1.00 & & \\
\hline Health center & & & & & & & 0.53 & 0.38 & $0.76^{* * *}$ \\
\hline Private facility & & & & & & & 1.56 & 0.54 & 4.55 \\
\hline Home & & & & & & & 0.47 & 0.39 & $0.56^{* * *}$ \\
\hline Other & & & & & & & 0.15 & 0.11 & $0.22^{* * *}$ \\
\hline \multicolumn{10}{|l|}{ SBA assisted } \\
\hline \multicolumn{10}{|l|}{ No } \\
\hline \multicolumn{10}{|l|}{ Yes } \\
\hline $\mathrm{N}$ & 9576 & & & 9576 & & & 5778 & & \\
\hline Log likelihood & $10,127.238$ & & & $10,127.238$ & & & 6589.391 & & \\
\hline$X^{2}$ test for model & $<0.01$ & & & $<0.01$ & & & $<0.01$ & & \\
\hline Hosmer-Lemeshow & 0.369 & & & 0.369 & & & 0.233 & & \\
\hline
\end{tabular}

$\mathrm{Cl}$ : confidence interval; $\mathrm{HHH}$ : head of household; OR: odds ratio; SBA: skilled birth attendant

${ }^{*} p<.10,{ }^{* *} p<.05,{ }^{* * *} p<.01$

a'Model 1: maternal, household and community variables only

bModel 2: maternal, household, community variables and birth attendance

'Model 3: maternal, household, community variables, birth attendance and delivery place

and knowledge about birth registration may exert a rapid effect on increasing the rate of birth registration in the Lao PDR. Such efforts will serve as a fundamental service from the government in the future.

In the multivariate analysis, not surprisingly, place of delivery was significantly associated with birth registration: the children who were born at a health center, at home or at other places were especially much less likely to have accessibility to birth registration. Only $65.0 \%$ of the children who were born at home had access to birth registration. This is 10 percentage points lower than the national representative average rate of birth registration of $75 \%$ [12]. Widely throughout Southeast Asian countries, and especially in the Lao PDR, home is the major place for the delivery of children $[20,21]$. One of the reasons for choosing home delivery is that Lao mothers expect to follow the traditional habit of staying by the fire during the perinatal period [20].

To improve access to proper birth registration especially in pockets of the Lao PDR, one possible approach could be capacity building of SBAs in the community to support mothers' access birth registration right after delivery [22].
The WHO Western Pacific Region Office has set a target to increase SBA-assisted delivery coverage to $90 \%$ by 2020 [23]. SBAs should instruct parents who choose a community-based delivery in the birth registration procedure. Although not addressed in this paper, $29.3 \%$ of children obtained a birth certificate. To guarantee continuum of care, improvement of the procedures to obtain not only birth registration but also to acquire a birth certificate are important issues. For maternal and child health, it is necessary to strengthen antenatal care and safe motherhood, the continuum of care leading to parental care, and the life-cycle approach throughout life. Birth certificates may be necessary for various events in life, such as for education or overseas travel. SBAs should also be required to play a role in assisting in the acquisition of birth certificates. For the Lao PDR, visualizing and counting all people, including those who are marginalized, is the most crucial step also from the perspective of universal health coverage (UHC) [24].

Although this study reached its aims and important policy implications can be drawn from the results, it 
does have an important limitation. The study was carefully prepared by conducting a statistical analysis using representative national data, but it is a secondary analysis using national data with limited available variables. Thus, conclusions about causality cannot be drawn, nor can all possible confounders be taken into account. Therefore, in terms of UHC, our analysis raises further questions about what are the other factors related to achieving birth registration in rural communities in the Lao PDR. Further investigation of birth registration is recommended to collect detailed community-based data that can contribute to improving accessibility to the birth registration system in the Lao PDR.

\section{Conclusions}

Our findings confirmed that ethno-geographic factors and place of delivery appear to be the two most significant factors associated with accessibility to birth registration in the Lao PDR. As one effective strategy to overcoming geographical disparity in the Lao PDR, where most mothers choose home delivery, we recommend community-based interventions that focus on capacity development of community health personnel such as the SBA.

\section{Abbreviations}

ASEAN: Association of Southeast Asian Nations; CHV: community health volunteer; CHW: community health worker; Lao PDR: Lao People's Democratic Republic; LSIS: Lao Social Indicator Survey; SBA: skilled birth attendant; SPSS: Statistical Package for Social Sciences; TBA: traditional birth attendant; UHC: universal health coverage; UNICEF: United Nations International Children's Emergency Fund; WHO: World Health Organization

\section{Acknowledgments}

We would like to acknowledge and thank the National Institute of Public Health in the Lao PDR for their technical and academic cooperation.

\section{Funding}

No funding was obtained for this study.

\section{Availability of data and materials}

Lao Social Indicator Survey 2011-12 (LSIS 2011-12) data is available at the National Statistical Bureau, Lao PDR.

\section{Authors' contributions}

MN wrote the first draft of the manuscript. All authors provided critical input and revisions for all further drafts. YK participated in the study design and managed initial data cleaning. $\mathrm{HO}$ collected supplemental information in the Lao PDR. XP and JK provided substantive local discussion on the manuscript. $\mathrm{KT}$ participated in the statistical analysis and provided supervision throughout. All authors read and approved the final manuscript.

\section{Ethics approval and consent to participate}

Ethical clearance to analyze the data was obtained from the ethical review committee, Lao National Institute of Public Health, Vientiane, Lao PDR (\#2016.2.MC).

\section{Consent for publication}

Not applicable.

\section{Competing interests}

The authors declare that they have no competing interests.

\section{Publisher's Note}

Springer Nature remains neutral with regard to jurisdictional claims in published maps and institutional affiliations.

\section{Author details}

Department of International Health and Collaboration, National Institute of Public Health, 2-3-6 Minami, Wako-shi, Saitama 351-0197, Japan. ${ }^{2}$ National Institute of Public Health, Vientiane, Lao PDR. ${ }^{3}$ Teikyo University, Tokyo, Japan. ${ }^{4}$ Ryukoku University, Kyoto, Japan. ${ }^{5}$ Yokkaichi Nursing and Medical Care University, Mie, Japan. ${ }^{6}$ Ryukyu University, Okinawa, Japan.

Received: 29 January 2017 Accepted: 20 December 2017

Published online: 08 January 2018

\section{References}

1. UN General Assembly. Convention on the Rights of the Child. United Nations, Treaty Series. 1989;1577:3.

2. UNICEF. Every Child's birth right: inequities and trends in birth registration. New York: UNICEF; 2013

3. UNICEF. Unequal at birth: disparities in birth registration in East Asia and the Pacific. Bangkok: UNICEF EAPRO; 2015.

4. UNICEF. The 'rights' start to life - a statistical analysis of birth registration 2005. New York: UNICEF; 2005.

5. Setel PW, Macfarlane SB, Szreter S, Mikkelsen L, Jha P, Stout S, et al. A scandal of invisibility: making everyone count by counting everyone. Lancet. 2007;370: 1569-77.

6. Horton R. Counting for health. Lancet. 2007;370:1526.

7. Todres J. Birth registration: an essential first step toward ensuring the rights of all children. Human Rights Brief. 2003;10:32-5.

8. Apland K, Hamilton C, Blitz BK, Hamilton C, Lagaay M, Lakshman R, et al. Birth registration and Children's rights: a complex story. London: Plan International; 2014.

9. Amo-Adjei J, Annim SK. Socioeconomic determinants of birth registration in Ghana. BMC Int Health Hum Rights. 2015;15:14.

10. Isara AR, Atimati AO. Socio-demographic determinants of birth registration among mothers in an urban community in southern Nigeria. J Med Trop. 2015:17:16-21

11. Adi AE, Abdu T, Khan A, Rashid MH, Ebri UE, Cockcroft A, Andersson N. Understanding whose births get registered: a cross sectional study in Bauchi and Cross River states, Nigeria. BMC Research Notes. 2015;8:79.

12. UNICEF. The state of the World's children 2015. New York: UNICEF; 2015.

13. Republic L P's D. Family registration law no. 03/PSA. People's Supreme Assembly: Vientiane; 1991.

14. WHO Commission on Social Determinants of Health. WHO: Closing the gap in a generation: Health equity through action on the social determinants of health: Commission on Social Determinants of Health final report. Geneva: World Health Organization, Commission on Social Determinants of Health; 2008

15. Ministry of Health and Lao Statistics Bureau. Lao People's Democratic Republic Special, 2011-12 - Lao Social Indicator Survey (MICS/DHS) Final Report (English) Vientiane: Ministry of Health and Lao Statistics Bureau; 2012.

16. The Seventh Five-year National SocioEconomic Development Plan (20112015). http://www.wpro.who.int/countries/lao/LAO20112015.pdf. Accessed 5 Dec 2016.

17. Silva R, Amouzou A, Munos M, Marsh A, Hazel E, Victora C, et al. Can community health workers report accurately on births and deaths? Results of field assessments in Ethiopia, Malawi and Mali. PLoS One. 2016;11: e0144662.

18. Afele M. Volunteers vital for counting births and deaths in Ghana. Bull World Health Org. 2011;89:322-3.

19. Fagernäs S, Odame J. Birth registration and access to health care: an assessment of Ghana's campaign success. Bull World Health Org. 2013;91:459-64.

20. Sychareun V, Hansana V, Somphet V, Xayavong S, Phengsavanh A, Popenoe R. Reasons rural Laotians choose home deliveries over delivery at health facilities: a qualitative study. BMC Pregnancy Childbirth. 2012:12:86.

21. Titaley CR, Hunter CL, Dibley MJ, Heywood P. Why do some women still prefer traditional birth attendants and home delivery? A qualitative study on delivery care services in west Java Province, Indonesia. BMC Pregnancy Childbirth. 2010;10:43.

22. UNICEF. A passport to protection. New York: UNICEF; 2013

23. WHO Regional Office for the Western Pacific. Action Plan for Healthy Newborn Infants in the Western Pacific Region (2014-2020). Manila: World Health Organization; 2014

24. Wong J. Achieving universal health coverage. Bull World Health Org 2015;93:663-4 